\title{
Effects of Resistance Footrest on Spine Posture in Visual Display Terminal Workers
}

\author{
Won-gyu Yoo, PT, PhD \\ Department of Physical Therapy, College of Health Care Medical Science and Engineering, Inje University, Gimhae, Korea
}

\author{
Article Info \\ Received March 17, 2021 \\ Revised April 20, 2021 \\ Accepted April 22, 2021 \\ Corresponding Author \\ Won-gyu Yoo \\ E-mail:won7y@inje.ac.kr \\ https://orcid.org/0000-0001-6200-9674
}

\section{Key Words}

Lumbar stability

Pevlic anterior tilt

Spine angle

\begin{abstract}
Background: Flat-back posture refers to a posture in which the pelvis is tilted backward, the lumbar spine is bent, the upper thoracic spine is increasingly bent, and the lower thoracic spine is straight. Given that most of the day is spent sitting, we need to develop exercise programs and devices that are suitable for people who spend less time exercising than sitting.

Objects: This study investigated the effects of resistance footrest exercise on spine posture angles in visual display terminal (VDT) workers with flat back.
\end{abstract}

Methods: We measured the upper lumbar angle (ULA) and lower lumbar angle (LLA) using a flexible ruler for the ULA and LLA. Then, after 1 week of resistance footrest exercise designed to strengthen the lumbar spine musculature, we measured these angles again. We measured each angle three times and then compared measurements from before and after exercise.

Results: There were no significant differences in the ULA following the strengthening exercise, but significant differences were observed in LLA.

Conclusion: The resistance footrest exercise strengthened the muscles affecting the pelvic and lumbar lordotic angles, and increases in the LLA were changed. This suggests that the role of the lower lumbar spine in the lumbar lordotic curve is greater than that of the upper lumbar spine. In addition, considering the contemporary tendency to lead fairly sedentary lives, these results indicate that exercising while seated can be effective.

\section{INTRODUCTION}

With the introduction of computers and mobile technology, the manner in which many people now perform their professional work has changed [1]. In 2015, the National Health Statistics released by the Ministry of Health and Welfare showed that Korean men and women spend 8 and 7.6 hours per day sitting, respectively. In addition, according to the Ministry of Labor and Welfare, China has designated visual display terminal (VDT) syndrome as a business injury and an occupational disease since 1994. Musculoskeletal symptoms are common among office workers, with a high proportion experiencing symptoms in the spine [2]. The arrangement of the spine is closely related to posture, and many previous studies have pointed out that the increase in sitting time is one source of disruption to the ideal arrangement of the spine and pelvis [3,4].

Compared to a standing position, during sitting, the pelvis is tilted backward, and the degree of lumbar lordosis is reduced
[5,6]. Previous studies have reported that lumbar lordosis is reduced by $50 \%$, and pelvic tilt (PT) is increased by $100 \%$ when participants move from a standing position to an erect sitting position $[7,8]$. Lumbar lordosis, which occurs in normal spinal alignment, is effective for maintaining functional motion, reducing the load on the spine, and increasing the efficiency of the muscles around the spine; together with the sagittal spinal curve, lumbar lordosis plays a role in maintaining an efficient upright posture [9]. However, the reduction in lumbar lordosis caused by prolonged sitting increases the load on the spine and causes abnormal pressure on joints, muscles, ligaments, and so on, all of which are related to occupational lower back pain [10-13]. Nachemson [14] reported that intradisc pressure increased by $40 \%$ during sitting compared to that in standing. Other previous studies have also reported greater stress on the spine when sitting than when standing due to increased lumbar flexion, which can lead to disc damage and low back pain (LBP) [10,15-17]. 
Kendall et al. [18] classified postures into four types according to pelvic and spinal alignment: ideal alignment, lordosis-kyphosis posture, curved-back posture, and flat-back posture. Flat-back posture refers to a posture in which the pelvis is tilted backward, the lumbar spine is bent, the upper thoracic spine is increasingly bent, and the lower thoracic spine is straight. In addition, the head is forward, the hip and knee joints are extended, and the ankle joint is slightly plantar flexed. It has been suggested that changes in posture are accompanied by changes in muscle length. Thus, in a particular posture, part of the musculature is strengthened or shortened, and the opposing muscle is weakened or increased.

Theoretically, the lengths of the muscles around the hip and the spinal muscles are closely related to pelvic tilting. In particular, the hip extensor muscles such as the gluteus maximus and hamstring cause the pelvis to tilt backward. By contrast, the hip flexor muscles, including the iliopsoas, tensor fascia latae, and rectus femoris, cause the pelvis to tilt forward. In addition, pelvic tilting is strongly correlated with lumbar movement and lumbar angle in a sitting position [19-22].

Based on the above theoretical framework, movement to correct a flat-back posture should include hip flexor motion that enhances pelvic forward tilt and lumbar extension [23]. Many exercise methods have been developed and clinically applied to enhance hip joint flexion in various positions, such as a standing position and a supine position. However, to correct flat-back posture, effective movement methods or devices that strengthen the hip flexor muscles in a seated position are inadequate. Although individually focused interventions such as sit-stand workstations are very popular, they are considerably more expensive than standard workstations, so their deployment may not be feasible in many workplaces, particularly in small offices or resource-constrained settings [24]. Given that most of the day is spent sitting, we need to develop exercise programs and devices that are suitable for people who spend less time exercising than sitting. Therefore, in this study, we investigated the effects of resistance footrest exercise on upper and lower lumbar angles in VDT workers with flat back.

\section{MATERIALS AND METHODS}

\section{Participants}

The subjects in this study were 12 VDT workers with flat back (3 men and 9 women) in their 20s who were enrolled in Gim- hae city. The distance from the T10 spinous process to the S2 spinous process in a straight standing position was measured in each subject using a $30 \mathrm{~cm}$ long flexible ruler. Those whose the sum of upper lumbar angle (ULA) (T10-L3) and lower lumbar angle (LLA) (L3-S2) was $<20^{\circ}$ were eligible for inclusion [25,26]. After the subjects fully understood the experimental method and purpose, they completed the consent form for participation in the experiment. Selection criteria were no record of surgery or injury to that lumbar and pelvic complex, no musculoskeletal or neurological diseases, and no scoliosis. The general characteristics of the subjects are shown in Table 1. Ethics approval was granted by Inje University Ethics Committee for Human Investigations, and written informed consent was obtained from all participants.

\section{Equipment}

\section{1) Flexible ruler and protractor}

A flexible ruler was used to measure the angle of the lumbar spine. To confirm the accuracy of the ruler, radiographs from 10 participants were considered, the lumbar lordosis angle was measured again with the flexible ruler, and then the two measurement results were compared. To visualize the lumbar lordosis angle measured using the flexible ruler, we used a protractor. This was considered evidence of validity [25]. To achieve natural curvature of the spine, the subjects stood in a comfortable position with their feet shoulder-width apart and their eyes facing forward; the angle of the lumbar spine was measured three times.

\section{2) Resistance footrest}

Subjects sat in a chair, leaning against the back. The sitdown resistance exercises foot support was used for the purpose of inducing pelvic anterior tilting and lumbar lordosis. While sitting, place your feet on the small wobble board and open your knees while sliding the board forward. In this time, the small wobble board provides an unstable support surface, and the thera-band attached to the back of the board resists forward movement of the foot. The small wobble board also

Table 1. General characteristics of the subject ( $N=12$ )

\begin{tabular}{cc}
\hline General characteristics & Average \pm standard deviation \\
\hline Age $(\mathrm{y})$ & $22.5 \pm 0.9$ \\
Height $(\mathrm{cm})$ & $167.2 \pm 3.2$ \\
Weight $(\mathrm{kg})$ & $66.2 \pm 5.0$ \\
\hline
\end{tabular}


has a horizontal meter, so it is designed to give visual feedback.

\section{Experimental Procedure}

\section{1) Flexible ruler and protractor measurement}

Lumbar curve was measured on the skin surface between T10 and S2. The ULA was measured using a protractor. When measuring the LLA, L3, which is the midpoint between T10 and S2, is considered the reference point [26]. Therefore, the first step of the examination was to measure the spinous processes of T10, L3, and S2 with the subject in a standing position. The location of the T10 spinous process, where the spine is connected to the 12 th rib on both sides, is the midpoint [27]. The experimenter first located the highest point on both iliac crests by palpation and then located the midpoint between them, which is the L3 spinous process [28], and the bulge above this, which is the L3 spinous process. The S2 spinous process corresponds to the midpoint of the posterior superior iliac spine [29]. Yellow adhesive tape was attached to the three contacts points, and the edge of the flexible ruler was placed along the spinal curve.

In the second step, the $0 \mathrm{~cm}$ mark on the ruler was placed at T10, and then the ruler was positioned along the other points. The locations of the markers along the ruler were recorded. Then the experimenter moved the ruler onto blank paper without changing its shape and fixed it there, and another experimenter traced the ruler's outline. Next, the ruler was moved, without altering its shape, to align the L3 point of the curve with the 0 -degree point on the protractor. Following the same procedure, the lumbar lordosis angle was measured three times on both sides based on T10 and S2. The angle recorded from the left side was used as the ULA, and that from the right side was the LA. The average ULA and LLA, as well as the standard deviations, were calculated; finally, the average value of the sum of ULA and LLA was calculated [25,26]. The same method was used to calculate results before and after exercise.

\section{2) Resistance footrest exercise}

Before movement, the angle between T10 and S2 was measured as described above. Then, participants sat in a chair with their back against the backrest. In this position, one foot was placed on the resistance footrest exercise apparatus, and the knee flexion/extension exercise was repeated for 15 minutes. Each foot was subjected to a 15-minute set of concentric contractions, for a total of 1 hour per day for 7 consecutive days.

\section{Analysis}

Data were analyzed using SPSS 18.0 for Windows (IBM Co., Armonk, NY, USA). To compare ULA, LLA before and after exercise, validation was performed using the appropriate Wilcoxon test. The significance level was set at $\mathrm{p}<0.05$.

\section{RESULTS}

The average angles before and after sitting exercises were compared. Increases in the ULA was not significant. However, the increase in the LLA angle was significant (Table 2).

\section{DISCUSSION}

Contemporary society has been described as an automated and mechanized society, and growing numbers of workers move very little, with many leading repetitive daily live [30]. Sitting for a long period of time causes the pelvis to tilt backward, increasing the curvature of the lumbar spine and causing flat back and other postural problems. It can also cause a range of health problems, including poor spinal alignment, increased blood pressure, shoulder and lower back pain, and so on [31-36]. In this study, we identified the effects of resistance footrest exercise on subjects with flat-back, and verified the efficacy and effectiveness of foot pedals for such exercise.

Assessment of the lumbar lordosis angle before and after the exercise intervention showed no significant change in ULA but a significant increase in LLA after exercise. In one study, L1L2 contributed to lumbar kyphosis, but the greatest lordosis of $7.3^{\circ}$ was observed from L3 to L5 [37]. Another reported lordosis percentages per segment of $5 \%$ at L1, 10\% at L2-3, 18\% at L3-4, 28\% at L4-5, and 39\% at L5-S1 [38]. The results of these two studies indicate that LLA predominates the lumbar lordosis angle. Our results are in line with these findings.

This is in contrast to Yoo [23], who conducted a 2-week intensive (30 reps $\times 3$ sets per day) exercise program targeting the erector spinae, iliopsoas, and rectus femoris in patients with LBP and flat-back posture. That study reported an in-

Table 2. Comparison of lumbar angles before and after exercise ( $N=12)$

\begin{tabular}{cccc}
\hline Classification & Before exercise & After exercise & p-value \\
\hline Upper lumbar angle $\left(^{\circ}\right)$ & $9.3 \pm 1.6$ & $11.5 \pm 2.6$ & 0.25 \\
Lower lumbar angle $\left(^{\circ}\right)$ & $8.5 \pm 1.8$ & $11.8 \pm 2.0$ & $0.01^{*}$ \\
\hline
\end{tabular}

$* p<0.05$. 
crease in $5^{\circ}$ and $6^{\circ}$ in the forward inclination of the left and right pelvis, respectively; it used an exercise intervention that only strengthened the rectus femoris, which may explain the differences. Kendall et al. [18] reported a tendency toward soleus muscle shortening in patients with reduced flat back or lumbar lordosis. Excessive soleus shortening reportedly causes the pelvis to tilt backward, thus reducing the lumbar lordosis angle. Therefore, exercise intervention programs for patients with flat back should strengthen the hip flexor group including the rectus femoris, with simultaneous stretching exercises for the soleus muscle [23]. However, the current study applied an intervention plan that only strengthened the rectus femoris, which may have limited the increase in pelvic anteversion.

In addition, exercise in the sitting position was also considered a possible factor in the absence of significant differences. Lumbar muscle activation is reduced with prolonged sitting [38]. In addition, a standing position can elicit the greatest segmental extension [39]. In a standing position, shortening of the hip flexors (iliopsoas, tensor fascia latae, rectus femoris) causes the pelvis to tilt forward, increasing the lumbar lordotic angle. However, in a seated position, the hip joint is flexed, which causes the hip flexor to relax, thereby reducing the effects of the hip flexors on lumbar lordosis [13,18]. Biomechanically, in a sitting position, the anterior lumbar column of the vertebra (i.e., the discs) receives greater compressive stress at the lumbosacral junction, whereas in a standing position, the posterior column (i.e., the facet joints) receives greater lordotic stress [9]. The fact that the hip flexors have different effects on PT in standing and sitting positions may have contributed to the absence of significant changes in PT after exercise in this study. At the same time, it is reasonable to assume that most people who work for a long time in a sitting position do not consciously adopt a slumped position. One of the problems with that position is that compared to most other situations, the muscles do not need to contract to achieve a sense of relaxation [40], although this position undoubtedly has the potential to cause health problems.

In the current study, although both men and women were included, possible differences between the genders were not analyzed. According to relevant previous studies, hip external rotation is greater in men than in women, and internal rotation is greater in women than in men [41]. In addition, men exhibit more lumbar flexion and less hip flexion than women during prolonged sitting. Furthermore, men display greater end-range lumbar flexion than women during both slumped sitting and forward bending [42]. Therefore, further studies may need to select more man and woman patients to analyze the role of gender in lumbar stability exercises.

In addition, some previous studies have shown that pelvic mobility is greater in a sitting than in a standing posture. Moreover, maximum pelvic anteversion angle and pelvic range of motion are greatly affected by age, likely because pelvic mobility may be directly affected by changes in lumbar mobility due to age $[8,43,44]$. In a study of middle-aged and old men and women, Zhou et al. [45] found that LLA was reduced by $40 \%$ when an upright sitting position was changed to a relaxed sitting position. By contrast, Hey et al. [46] showed that in young people it may be reduced by $80 \%$. The older individuals' spines still maintained an S-shaped curve in the natural sitting position, which differed from the C-shaped curve observed in young adults. This finding might be due to poor lumbosacral mobility and degeneration of the posterior ligaments and muscle complex in older adults. Therefore, in the future, not only the influence of gender but also differences among age groups must be considered in determining whether intensive exercise training of the hip flexor muscles is beneficial for all workers, including men and women of varying ages who need to sit for prolonged periods.

In this study, the hip flexor muscles were strengthened using a resistance foot exercise (lumbar spine stability strengthening device), and the results showed that this might be effective for increasing the lumbar lordosis angle and preventing flat back. Especially considering the characteristics of today's lifestyles, which often require prolonged sitting, it would be advantageous to perform various tasks while sitting and be able to exercise at the same time. This study had several limitations. First, we included only 12 subjects thus it is difficult to obtain generalize experimental results. Second, the duration of exercise intervention was just 7 consecutive days at 30 minutes per day. The time for muscle strength training is short. Third, due to the nature of Thera-Band, the precise level of resistance could not be quantified. Future studies will require exercise interventions that compensate for these limitations.

\section{CONCLUSIONS}

The effects of resistance footrest exercise on subjects with a flat lumbar spine were compared. When using sitting trunk 
stability and hip flexor resistance exercises for the purpose of inducing pelvic anterior tilting and lumbar lordosis, resulted in a significant increase in LLA.

\section{ACKNOWLEDGEMENTS}

This work was supported by the National Research Foundation of Korea (NRF) grant funded by the Korea government (MSIT) (No. NRF-2020R1F1A1049191).

\section{CONFLICTS OF INTEREST}

No potential conflict of interest relevant to this article was reported.

\section{REFERENCES}

1. Egger M, Davey Smith G Altman DG. Systematic reviews in health care: meta-analysis in context. London: BMJ; 2001.

2. Janwantanakul P, Pensri P, Jiamjarasrangsri V, Sinsongsook T. Prevalence of self-reported musculoskeletal symptoms among office workers. Occup Med (Lond) 2008;58(6):436-8.

3. Lee CH, Jeong YT, Kim HC, Yoo HS. Comparison of physique, physical fitness and mental health between spinal scoliotic and normal students. Korean J Growth Dev 2006;14(2):8794.

4. Moon JH. Position improvement strategy for the spinal health in the school children. J Korean Soc School Health 1998;11(1):7-10.

5. De Carvalho DE, Soave D, Ross K, Callaghan JP. Lumbar spine and pelvic posture between standing and sitting: a radiologic investigation including reliability and repeatability of the lumbar lordosis measure. J Manipulative Physiol Ther 2010;33(1):48-55.

6. Cho IY, Park SY, Park JH, Kim TK, Jung TW, Lee HM. The effect of standing and different sitting positions on lumbar lordosis: radiographic study of 30 healthy volunteers. Asian Spine J 2015;9(5):762-9.

7. Hey HWD, Teo AQA, Tan KA, Ng LWN, Lau LL, Liu KG, et al. How the spine differs in standing and in sitting-important considerations for correction of spinal deformity. Spine J 2017;17(6):799-806.

8. Endo K, Suzuki H, Nishimura H, Tanaka H, Shishido T, Yamamoto K. Sagittal lumbar and pelvic alignment in the standing and sitting positions. J Orthop Sci 2012;17(6):682-6.

9. Moon MS, Lee H, Kim ST, Kim SJ, Kim MS, Kim DS. Spinopelvic orientation on radiographs in various body postures: upright standing, chair sitting, Japanese style kneel sitting, and Korean style cross-legged sitting. Clin Orthop Surg 2018;10(3): 322-7.

10. Shin SS, Shin GC, Kim DH, Sim HM, Jeong JG, Yoo WG. The effects of a posterior superior iliac spine support device on upper trunk acceleration during gait in individuals with flat lumbar back posture. Technol Health Care 2018;26(5):873-8.

11. Makhsous M, Lin F, Bankard J, Hendrix RW, Hepler M, Press J. Biomechanical effects of sitting with adjustable ischial and lumbar support on occupational low back pain: evaluation of sitting load and back muscle activity. BMC Musculoskelet Disord 2009;10:17.

12. Green JP, Grenier SG, McGill SM. Low-back stiffness is altered with warm-up and bench rest: implications for athletes. Med Sci Sports Exerc 2002;34(7):1076-81.

13. Lengsfeld M, Frank A, van Deursen DL, Griss P. Lumbar spine curvature during office chair sitting. Med Eng Phys 2000;22(9):665-9.

14. Nachemson AL. Disc pressure measurements. Spine (Phila Pa 1976) 1981;6(1):93-7.

15. Castanharo R, Duarte M, McGill S. Corrective sitting strategies: an examination of muscle activity and spine loading. J Electromyogr Kinesiol 2014;24(1):114-9.

16. Kim SH, Kwon OY, Yi CH, Cynn HS, Ha SM, Park KN. Lumbopelvic motion during seated hip flexion in subjects with lowback pain accompanying limited hip flexion. Eur Spine J 2014;23(1):142-8.

17. Callaghan JP, McGill SM. Low back joint loading and kinematics during standing and unsupported sitting. Ergonomics 2001;44(3):280-94.

18. Kendall FP, McCreary EK, Provance PG. Muscles: testing and function with posture and pain. Baltimore: Lippincott Williams \& Wilkins; 2005;516.

19. Link CS, Nicholson GG, Shaddeau SA, Birch R, Gossman MR. Lumbar curvature in standing and sitting in two types of chairs: relationship of hamstring and hip flexor muscle length. Phys Ther 1990;70(10):611-8.

20. Kuo YL, Tully EA, Galea MP. Video analysis of sagittal spinal posture in healthy young and older adults. J Manipulative Physiol Ther 2009;32(3):210-5.

21. Kobayashi T, Atsuta Y, Matsuno T, Takeda N. A longitudinal 
study of congruent sagittal spinal alignment in an adult cohort. Spine (Phila Pa 1976) 2004;29(6):671-6.

22. Amonoo-Kuofi HS. Changes in the lumbosacral angle, sacral inclination and the curvature of the lumbar spine during aging. Acta Anat (Basel) 1992;145(4):373-7.

23. Yoo WG. Effect of individual strengthening exercises for anterior pelvic tilt muscles on back pain, pelvic angle, and lumbar ROMs of a LBP patient with flat back. J Phys Ther Sci 2013;25(10):1357-8.

24. Shrestha N, Kukkonen-Harjula KT, Verbeek JH, Ijaz S, Hermans V, Pedisic Z. Workplace interventions for reducing sitting at work. Cochrane Database Syst Rev 2018;6(6):CD010912.

25. Seidi F, Rajabi R, Ebrahimi TI, Tavani AR, Moussavi SJ. The Iranian flexible ruler reliability and validity in lumbar lordosis measurements. World J Sport Sci 2009;2(2):95-9.

26. Shin SS, Yoo WG. Inter-tester reliability of lumbar lordosis posture classification using a novel screening device. J Manipulative Physiol Ther 2021;44(1):35-41.

27. Youdas JW, Garrett TR, Harmsen S, Suman VJ, Carey JR. Lumbar lordosis and pelvic inclination of asymptomatic adults. Phys Ther 1996;76(10):1066-81.

28. Chakraverty R, Pynsent P, Isaacs K. Which spinal levels are identified by palpation of the iliac crests and the posterior superior iliac spines? J Anat 2007;210(2):232-6.

29. Mirbagheri SS, Rahmani-Rasa A, Farmani F, Amini P, Nikoo MR. Evaluating kyphosis and lordosis in students by using a flexible ruler and their relationship with severity and frequency of thoracic and lumbar pain. Asian Spine J 2015;9(3):416-22.

30. Park SA, Lee KI, Kim KY. Daily living habits and knowledge of good posture among the middle school students. J Sport Leis Stud 2008;(33):603-14.

31. Womersley L, May S. Sitting posture of subjects with postural backache. J Manipulative Physiol Ther 2006;29(3):213-8.

32. Hakala PT, Rimpelä AH, Saarni LA, Salminen JJ. Frequent computer-related activities increase the risk of neck-shoulder and low back pain in adolescents. Eur J Public Health 2006;16(5):536-41.

33. Gupta N, Christiansen CS, Hallman DM, Korshøj M, Carneiro IG, Holtermann A. Is objectively measured sitting time associated with low back pain? A cross-sectional investigation in the NOMAD study. PLoS One 2015;10(3):e0121159.

34. Lis AM, Black KM, Korn H, Nordin M. Association between sitting and occupational LBP. Eur Spine J 2007;16(2):283-98.

35. Wahlström J. Ergonomics, musculoskeletal disorders and computer work. Occup Med (Lond) 2005;55(3):168-76.

36. Ariëns GA, Bongers PM, Douwes M, Miedema MC, Hoogendoorn WE, van der Wal G, et al. Are neck flexion, neck rotation, and sitting at work risk factors for neck pain? Results of a prospective cohort study. Occup Environ Med 2001;58(3): 200-7.

37. Kim DS, Kim YM, Choi ES, Shon HC, Park KJ, Park GK, et al. Shape and motion of each lumbar segment in normal Korean adults. J Korean Orthop Assoc 2008;43(5):595-600.

38. Ringheim I, Indahl A, Roeleveld K. Reduced muscle activity variability in lumbar extensor muscles during sustained sitting in individuals with chronic low back pain. PLoS One 2019;14(3):e0213778.

39. Alamin TF, Agarwal V, Zagel A, Qeli A. The effect of standing vs. variants of the seated position on lumbar intersegmental angulation and spacing: a radiographic study of 20 asymptomatic subjects. J Spine Surg 2018;4(3):509-15.

40. O’Sullivan PB, Grahamslaw KM, Kendell M, Lapenskie SC, Möller NE, Richards KV. The effect of different standing and sitting postures on trunk muscle activity in a pain-free population. Spine (Phila Pa 1976) 2002;27(11):1238-44.

41. Han H, Kubo A, Kurosawa K, Maruichi S, Maruyama H. Hip rotation range of motion in sitting and prone positions in healthy Japanese adults. J Phys Ther Sci 2015;27(2):441-5.

42. Hoffman SL, Johnson MB, Zou D, Van Dillen LR. Differences in end-range lumbar flexion during slumped sitting and forward bending between low back pain subgroups and genders. Man Ther 2012;17(2):157-63.

43. Intolo P, Milosavljevic S, Baxter DG, Carman AB, Pal P, Munn J. The effect of age on lumbar range of motion: a systematic review. Man Ther 2009;14(6):596-604.

44. Asai H, Tsuchiyama H, Hatakeyama T, Inaoka PT, Murata K. Age-related changes in maximum pelvic anteversion and retroversion angles measured in the sitting position. J Phys Ther Sci 2014;26(12):1959-61.

45. Zhou S, Li W, Wang W, Zou D, Sun Z, Xu F, et al. Sagittal spinal and pelvic alignment in middle-aged and older men and women in the natural and erect sitting positions: a prospective study in a Chinese population. Med Sci Monit 2020;26: e919441.

46. Hey HW, Wong CG, Lau ET, Tan KA, Lau LL, Liu KG, et al. Differences in erect sitting and natural sitting spinal alignmentinsights into a new paradigm and implications in deformity correction. Spine J 2017;17(2):183-9. 